\title{
Primavera en las galerías de arte dr de Shanghái (China)
}

\section{Artículo de reflexión}

\section{Adrià Harillo Pla}

Universidad Complutense de Madrid, España

adria.harillo@gmail.com

Recibido: 9 de agosto de 2017

Aprobado: 2 de enero de 2018

Cómo citar este artículo: Harillo Pla, Adrià (2018).

Primavera en las galerías de arte de Shanghái. Calle14: revista de investigación en el campo del arte 13 (24) pp. 428-436. DOI: https://doi.org/10.14483/21450706. 13536

Agradecimientos: Este artículo ha sido posible gracias a la financiación, de forma directa o indirecta, de la Fundación para el Fomento en Asturias de la Investigación Científica Aplicada y la Tecnología y el Ministerio de Educación, Cultura y Deporte de España. 


\title{
Resumen
}

El presente artículo es una crítica artística a diferentes obras de arte y propuestas expositivas presentes en diferentes galerías de arte contemporáneo ubicadas en M50, el distrito del arte de la ciudad de Shanghái, la capital económica de China. Semejante crítica coincide con las exhibiciones en un contexto tan importante como es la primavera en China, momento del año que tiene un gran papel en la larga historia del arte en ese país. Mediante el presente artículo el autor tiene la pretensión de aproximar algunos de los artistas y obras actualmente expuestos a la comunidad latinoamericana, algo que, debido a las particularidades del país asiático, puede ser complejo en algunas ocasiones.

\section{Palabras claves}

Arte contemporáneo, filosofía del arte, mercado del arte, galerías de arte; China.

\section{Spring in the art galleries of Shanghai}

\begin{abstract}
This article is an artistic criticism of different artworks and curatorial proposals to be found in different contemporary art galleries located in M50, the art district of the city of Shanghai, the economic capital of China. Such criticism coincides with these exhibitions in a context as important as spring in China, a time of the year that has played a large role throughout the history of art in that country. By means of this article, the author tries to bring closer some of the artists and artworks currently exhibited to the Latin American community, something that can be sometimes difficult due to the peculiarities of the Asian country.
\end{abstract}

\section{Keywords}

Contemporary art, philosophy of art, art market, art galleries, China.

\section{Printemps aux galeries d'art de Shanghai}

\section{Résumé}

Le présent article est une critique artistique de différentes œuvres d'art et propositions d'expositions présentes dans différentes galeries d'art contemporain situées au M50, le quartier des arts de la ville de Shanghai, capitale économique de la Chine. Une telle critique coïncide avec les exhibitions dans un contexte aussi important que le printemps en Chine, une période de l'année qui a un grand rôle dans la longue histoire de l'art dans ce pays. A travers cet article, l'auteur a la prétention de rapprocher certains des artistes et des œuvres actuellement exposés à la communauté latino-américaine, ce qui, en raison des particularités du pays asiatique, peut s'avérer complexe à certaines occasions.

\section{Mots clés}

Art contemporain, philosophie de l'art, marché de l'art, galeries d'art, Chine.

\section{Primavera nas galerias de arte de Xangai}

\section{Resumo}

O presente artigo é uma crítica artística de diferentes obras de arte e propostas de exposições presentes em diferentes galerias de arte contemporânea localizadas no M50, o distrito de arte da cidade de Xangai, a capital econômica da China. Tal crítica coincide com as apresentações em um contexto tão importante quanto a primavera na China, uma época do ano que tem um grande papel na longa história da arte naquele país. Através deste artigo, o autor tem a pretensão de 
aproximar alguns dos artistas e obras atualmente expostos à comunidade latino-americana, algo que, devido às particularidades do país asiático, pode ser complexo em algumas ocasiões.

\section{Palavras chaves}

Arte contemporânea, filosofia da arte, mercado de arte, galeria de arte, China.

\section{Maillallachiska:}

Kai kilkaipi ninakumi iman kawachin chi sugpi sugpi imasa kaska kai atun llagta china sutipi rurankunami llapa suma parlai kawachispa, ñugpamanda kulkiwa Tukui kangapa kai parlapi kawachikumi kai warmi suti llukanchimi Tukui allilla iuaringa chasa pudinchimi kausanga sumaglla.

\section{Rimangapa Ministidukuna:}

Rurai tukuikunamanda, allilla kawangapa, kawaspa katungapa, Tukui iullarispa, China chasa sutillagta, kawachingapa. 
Aun cuando no es el propósito de este artículo el efectuar una descripción del folclore del país asiático, resulta conveniente advertir un hecho destacable para un mayor entendimiento del análisis que en este ensayo se desarrollará y es que China es un país en el que, a pesar de su increíble desarrollo en las actuales fechas, las tradiciones no han menguado apenas un ápice y en el que el papel de las cuatro estaciones del año es esencial. Una muestra manifiesta de ello es que las dos principales festividades chinas son el denominado Fin de Año Nuevo Chino y la Fiesta del Medio Otoño, respectivamente. A diferencia de lo que ocurre en la mayoría de países, el Fin de Año Nuevo Chino no tiene lugar nunca en la misma fecha, sino que depende del calendario lunar y solar. Cabe agregar que en China semejante festividad es conocida con el nombre de Fiesta de la Primavera (春节), lo que notoriamente indica la importancia de dicha estación del año en la longeva cultura del gigantesco país oriental. ${ }^{1}$

Después de lo anteriormente expuesto resulta oportuno adentrarse en el objeto de observación que nos ocupa, a saber, las exposiciones de arte que se hallaron presentes en esta primavera en diferentes galerías de arte contemporáneo ubicadas en M50, el distrito de las artes de la ciudad de Shanghái, la cual detenta el honor de ser la capital económica de la China continental y posiblemente su ciudad más internacional.

Como resultado de esta internacionalización podría pensarse que Shanghái no es el lugar idóneo para reparar en la presencia de la cultura tradicional china en el arte, y eso es en gran medida cierto. De hecho $-y$ aun a sabiendas de que no son referencias oficiales- se calcula que solamente un $20 \%$ de personas que viven en Shanghái son shanghainesas. Este hecho diluye vastamente la cultura tradicional del lugar, aunque le procura otros influjos culturales sugestivos. En este sentido y dirección no es menos cierto, a su vez, que una innumerable cantidad de ese $80 \%$ de sujetos que viven en Shanghái, pero no son shanghaineses son foráneos nacionales $y$, por ende, deben ser considerados como

1 Aun cuando una consulta veloz a cualquier manual de Historia del arte o Historia del arte asiático pueden corroborar esta afirmación, de forma más particular, el autor del artículo trabajó en un museo barcelonés en el que se llevó a cabo una exposición del artista chino He Jiaying. El citado pintor es eminentemente popular por sus pinturas relacionadas con las estaciones. La exposición fue una de las más exitosas -en visitantes y crítica- de la historia del museo. Este hecho demuestra que el rol de las estaciones sigue presente no solamente en la sociedad china, sino también en sus artistas más actuales y en la mentalidad del público como algo asociado al arte oriental.

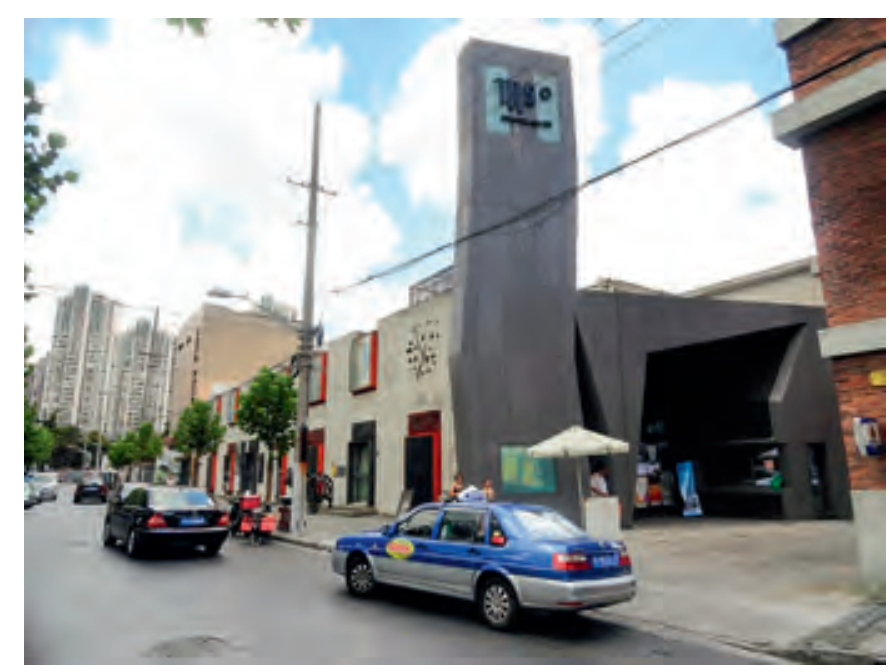

Imagen 1. Entrada a M50. Fuente: Flickr. @ CC BY-SA 4.0

casos de inmigración interna. Estos individuos, al ser ciudadanos chinos, contribuyen en gran medida a la preservación de la cultura china en esta descomunal ciudad, a pesar de las disimilitudes culturales específicas que puedan existir entre diferentes regiones. ${ }^{2}$

Como consecuencia de la importancia de la primavera en la sociedad china y si se accede a aceptar el arte como fruto de la actividad humana y, por lo tanto, como resultado de un tiempo, un lugar y unos sujetos particulares, la primavera debería estar presente de un modo u otro en la obra de algunos de los artistas expuestos en M50 en la actualidad. ${ }^{3}$ En el marco de estas obser-

2 Demográficamente, a pesar de que China crece y ya supera en ciudades de más de un millón de habitantes a países como Estados Unidos, la población china sigue siendo eminentemente rural. De hecho, el programa comunista de Mao dotó de un papel principal a los campesinos, a diferencia del comunismo acontecido en la Unión Soviética en el que el principal grupo generador de trabajo era el asalariado industrial. Estas particularidades de naturaleza histórica y demográfica son las causas que conllevan que muchos habitantes chinos emigren a grandes ciudades como Shanghái, Pekín, Cantón, entre otras.

$3 \quad$ Algunos académicos han defendido que el arte no es tanto un ejemplo - en tanto que producto- de una sociedad sino un instrumento transformador de esta, o ambas cosas recíprocamente. Semejante discusión excedería sobremanera la extensión y objetivo de este artículo y, a pesar de que es un debate todavía activo, la segunda de las opciones no aporta nada a nuestro discurso. Por otro lado, hay quienes defienden que el arte se ocupa, desde un punto de vista esencialista, de cuestiones universales y eternas. En este caso, podría pensarse que la primavera no debería tener aquí una importancia significativa. Esta negación, sin embargo, sería un error pues más allá de posturas personales con respecto a esta cuestión, en tanto que natural, la primavera debería ser considerada como un universal, aun cuando los diferentes núcleos culturales desarrollen diferentes concepciones teóricas y mentales sobre ella. 


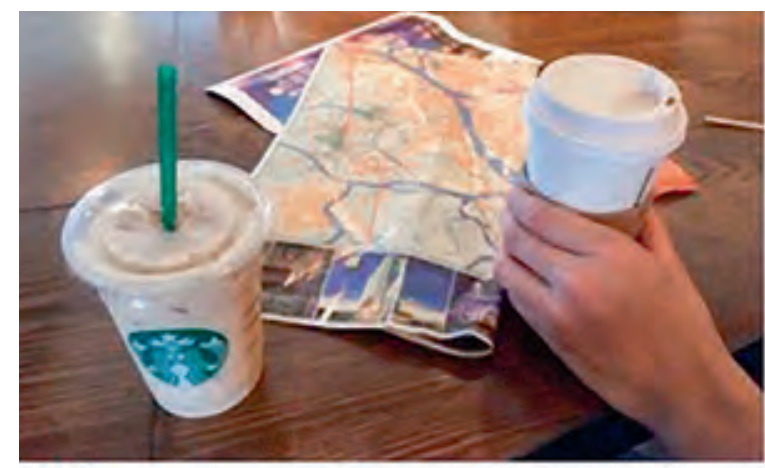

lestin.

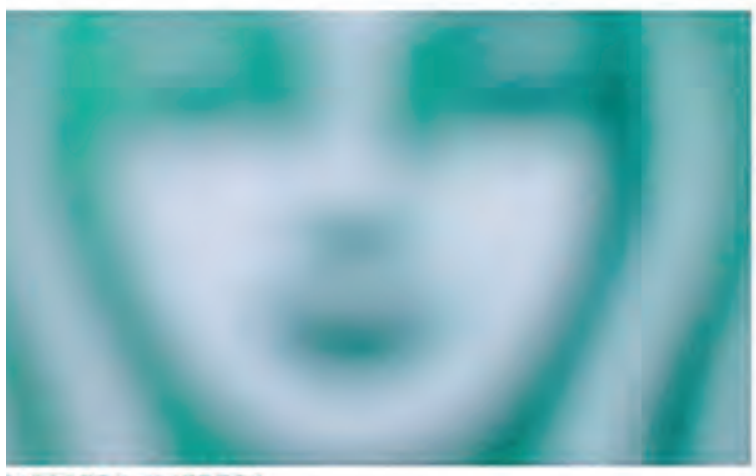

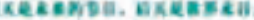

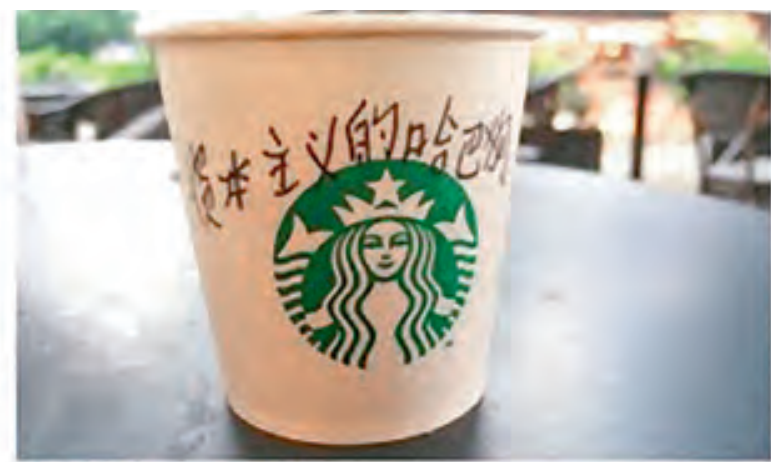

Qsisneen.

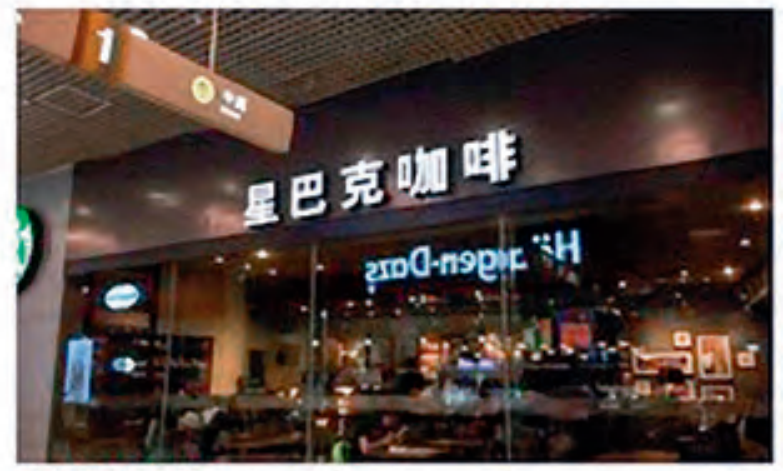

netarakuses.

Imagen 2. Fotogramas de "Starbucks Left" de Lin Aojie. Cortesía de la artista y "A+ Contemporary".

vaciones debe manifestarse que la visita del autor a M50 fue la más grata desde que abandonó su ocupación en una de las galerías del citado distrito e, incluso, desde que llegó a Shanghái. Cabe agregar, empero, que semejante satisfacción dista mucho de lo deseable y de lo que cabría esperar de una ciudad con semejantes particularidades. ${ }^{4}$ Debe advertirse también al lector que no todas las obras presentadas son piezas necesariamente realizadas en este período, pero sí que han sido seleccionadas por los directores, comisarios... para ser mostradas al público en el contexto referido.

4 La visita, en este caso, proporcionó experiencias más enriquecedoras que antaño. A pesar de este hecho y como se verá, se sigue pecando de mala gestión, poca originalidad y superficialidad. Esto no es contradictorio con el momento económico y las circunstancias demográficas en tanto que, por un lado, habría quien pudiese sentirse tentado a afirmar que, si el arte se entiende como un producto de lujo, si el mercado pide arte de calidad en un país en bonanza económica, el mercado lo proporcionará ya que existe el suficiente poder monetario para adquirirlo a pesar de los elevados precios. El dinero es, no obstante, un método utilizado para mostrar prioridades, no calidades. Además, el hecho de pensar que a mayor cantidad de población -y artistas potenciales-, mejor calidad artística es un error. Desde un punto de vista cuantitativo sería una posible consecuencia, pero no cualitativamente, lo que convierte a esta afirmación en posible, pero no en certera per se.
Como venimos diciendo, algunas de las piezas observadas fueron más atrayentes de lo usual. Entre ellas podría aludirse a la creación de Lin Aojie titulada Starbucks Left y presentada en A+ Contemporary. La pieza se halla constituida por un video a color y sin sonido de tres minutos y treinta y siete segundos en los que el artista muestra imágenes relacionadas con la reconocidísima cadena de restauración norteamericana Starbucks. Estas se muestran acompañadas de mensajes sarcásticos sobre la empresa y las relaciones de esta con los clientes o a la inversa -esto es de los clientes con la empresa-. Esta obra de la cual Lin Aojie ha creado cinco ediciones es crítica con la empresa, pero especialmente con algunas actitudes de sus consumidores y, por ende, es una reprobación al consumo generalizado que comporta el dispendio y el poder simbólico de las marcas, algo que en China se encuentra a la orden del día en cotas inimaginables. En efecto, la propuesta tiene algo de interesante, mas no deja de ser una crítica poco innovadora y no detenta, ni por asomo, la capacidad de modificar a la sociedad - capacidad que los más candorosos defensores del arte todavía defienden-.

Algo similar al anterior caso puede hallarse en Cc Foundation, la galería de David Chau y en la que, en esta 
circunstancia, lo más señalado es una instalación consistente en el lanzamiento de pequeñas bolas de metal desde un dispositivo albergado en la pared. Las esferas en cuestión caen al suelo de tapiz y, por reiteración, decoloran la moqueta, la agujerean y se instalan en el orificio o parten despedidas hacia otros lugares -que, por razones de física, son casi siempre análogos- ${ }^{5}$

A partir de ahí, se puede reparar en la contribución del grupo Liu Dao en su galería-residencia, island6 Arts Center. Este grupo llama la atención la primera vez que uno se enfrenta a sus obras por lo vistoso de sus leds interactivos y demás tecnología utilizada, pero con el paso del tiempo ha terminado siendo siervo de lo insustancial e intranscendente -y no por su modo de plasmar la sociedad actual, sino por ineptitud evolutiva- También puede advertirse otra representación, en este caso en Chronus Art Center denominada Lu Yang Desilusional Mandala. Este vídeo consigue que el público empiece a observar en gran parte debido a los colores y sonidos utilizados, no obstante, su inacabable durabilidad y lo inofensivo en lo que deriva su comunicación terminan por hastiar. En el caso de Problematic GIFs _ No problem at all de Miao Ying, la artista nacida en Shanghái pero residente entre Nueva York y Shanghái hace uso de GIFs o populares stickers utilizados en WeChat, la aplicación de mensajería instantánea por antonomasia en China y cuyas características más similares podrían ser las del occidental Whatsapp. El uso de estos materiales y recursos visuales no son nada insólito ni constitutivo de creación artística pues, ya en marzo de 2013 el Museo Stedelijk de Ámsterdam presentó algo parecido y con insignificantes diferencias, si bien en aquella ocasión el museo holandés lo hizo haciendo uso de populares videos de Youtubey añadió tres pantallas que alternaban los vídeos. ${ }^{6}$

Hechas las consideraciones anteriores -y para no faltar a la verdad- es el momento de emprender el camino por lo más deslucido de M50 en esta temporada de entretiempo. Los desaciertos son,

\footnotetext{
$5 \quad$ El método, despertó en la mente del autor del artículo la imagen de la tortura de la gota china.

$6 \quad$ El ready-made nos enseñó que hoy para producir arte no hace falta ser original. Tampoco hace falta utilizar nuevos materiales, algo que de hecho nunca se ha realizado pues ya los pintores clásicos utilizaban todos ellos pinturas y lienzo, por ejemplo. A pesar de ello y haciendo referencia indirecta a Danto - principal teórico que reflexionó acerca de este movimiento y que muchas veces es citado sin el suficiente conocimiento de su bibliografía- podríamos decir que una vez hecho, no tenía sentido volverlo hacer. La misma reflexión llevada a cabo por el estadounidense podría aplicarse a este caso.
}

esencialmente, los mismos que en el pasado y, como no podría ser de otro modo, cometidos por casi idénticos protagonistas. Por un lado, en "Leung Gallery" uno alcanza a ver en las dos plantas en las que se halla organizada una gran cantidad de piezas entre cuadros, jarrones... todo ello con la firma de Leung y con el símbolo "(C)". Esto no solamente no dota de una mayor legalidad y/o derechos de autor al artista que - a su vez - también se auto-representa, sino que semejante inserción del símbolo en el cuadro transfiere, casi exclusivamente, el efecto de mera mercadería y de mácula. Esta sensación se halla exponencialmente incrementada considerando que la eventual transacción de la obra se realiza en una galería de arte y, por consiguiente, podría requerirse de un certificado de autenticidad con información pormenorizada acerca de las singularidades de lo adquirido por parte del coleccionista, lo que anula el ya de por si innecesario requisito de agregar el símbolo en cuestión.

Distinto (aunque con idéntico resultado cualitativo) es el caso de X-Power Gallery o su galería limítrofe. En esta ocasión, el yerro sucede por hecho de vender arte de forma conjunta con, por ejemplo, geles fijadores de cabello en el primero de los espacios. Sobra decir que ello manifiesta mucho anhelo de expender, pero muy poca conciencia acerca del qué. La galería adyacente, como decíamos, no se encuentra liberada de desaciertos. Si bien en este caso solamente se vende arte, no hay un cuadro suspendido a la misma altura o de forma recta. Debe añadirse que, en lo tocante a la iluminación, ignominiosa, esta consolida los problemas de la galería, que en esta ocasión no se hallan tan asociados al qué, sino al cómo.

Sobretexto del caso de X-Power Gallery nos encontramos con la responsabilidad de declarar que el error no consiste única y peculiarmente en el citado espacio, pues pueden verse galerías de arte vendiendo fruta en su interior juntamente con libretas del Museo Picasso de París, un género tan diverso y forastero que no precisa de mayores disquisiciones. Cabe agregar, a su vez, el caso de Mycenae Gallery, espacio expositivo en el que no se vende exclusivamente arte, sino que también se vende vino español.7 Mayor desconcierto causa la

\footnotetext{
7 Habrá quien se sienta tentado a postular que el vino es arte, y posiblemente no estaría falto de razones. Sin embargo, sería arte culinario, gustativo, vinícola o de cualquier otra categoría, pero por supuesto, no plástico o visual. Al ser arte no en el sentido de las Bellas Artes - que, aunque ya no son bellas y se han amplificado son las que se siguen asociando a las galerías-consideramos aquí esto un error.
} 


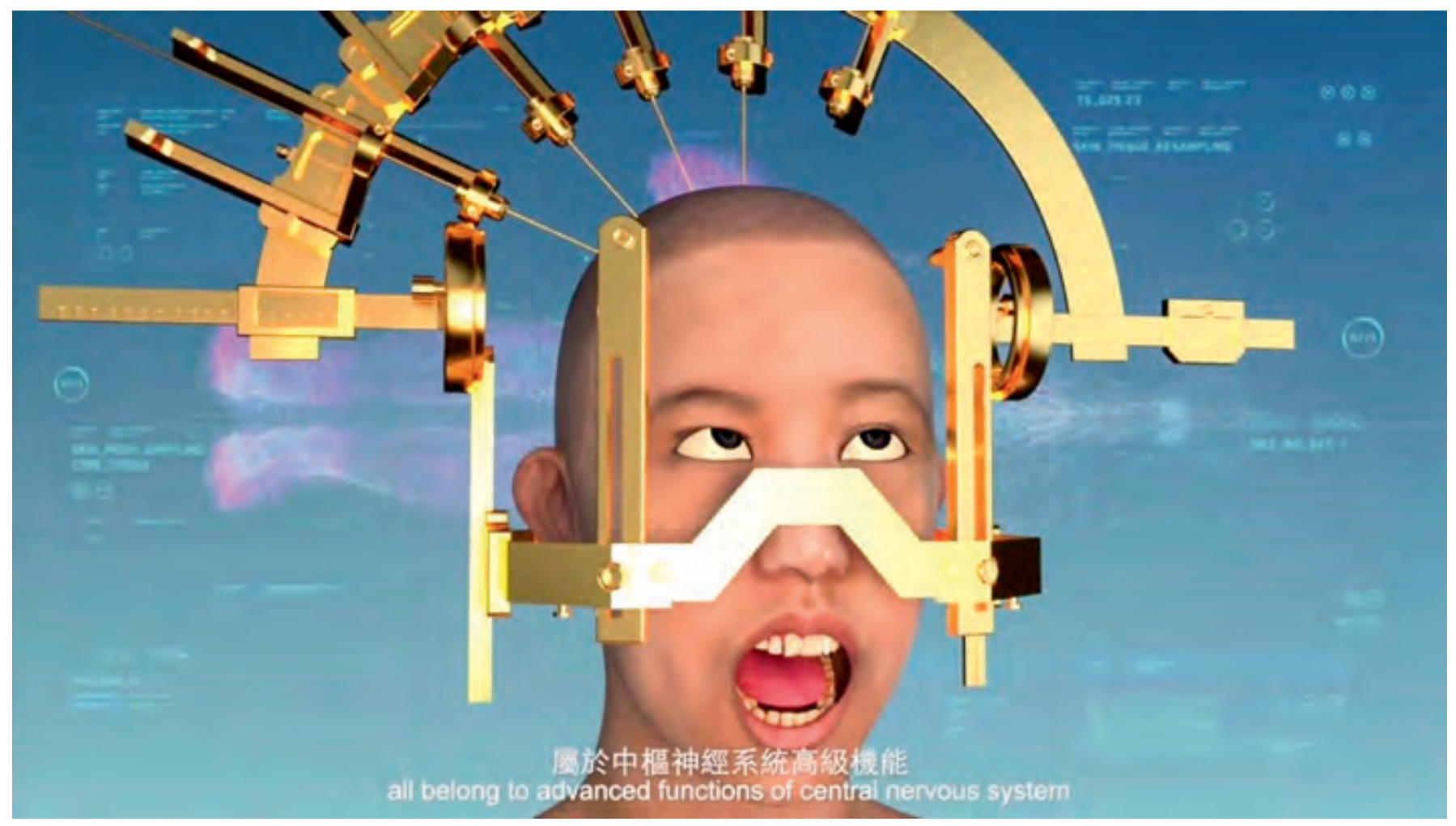

Imagen 3. Fotograma de "Lu Yang Desilusional Mandala" de Lu Yang. Cortesía de la artista y "Chronus Art Center".

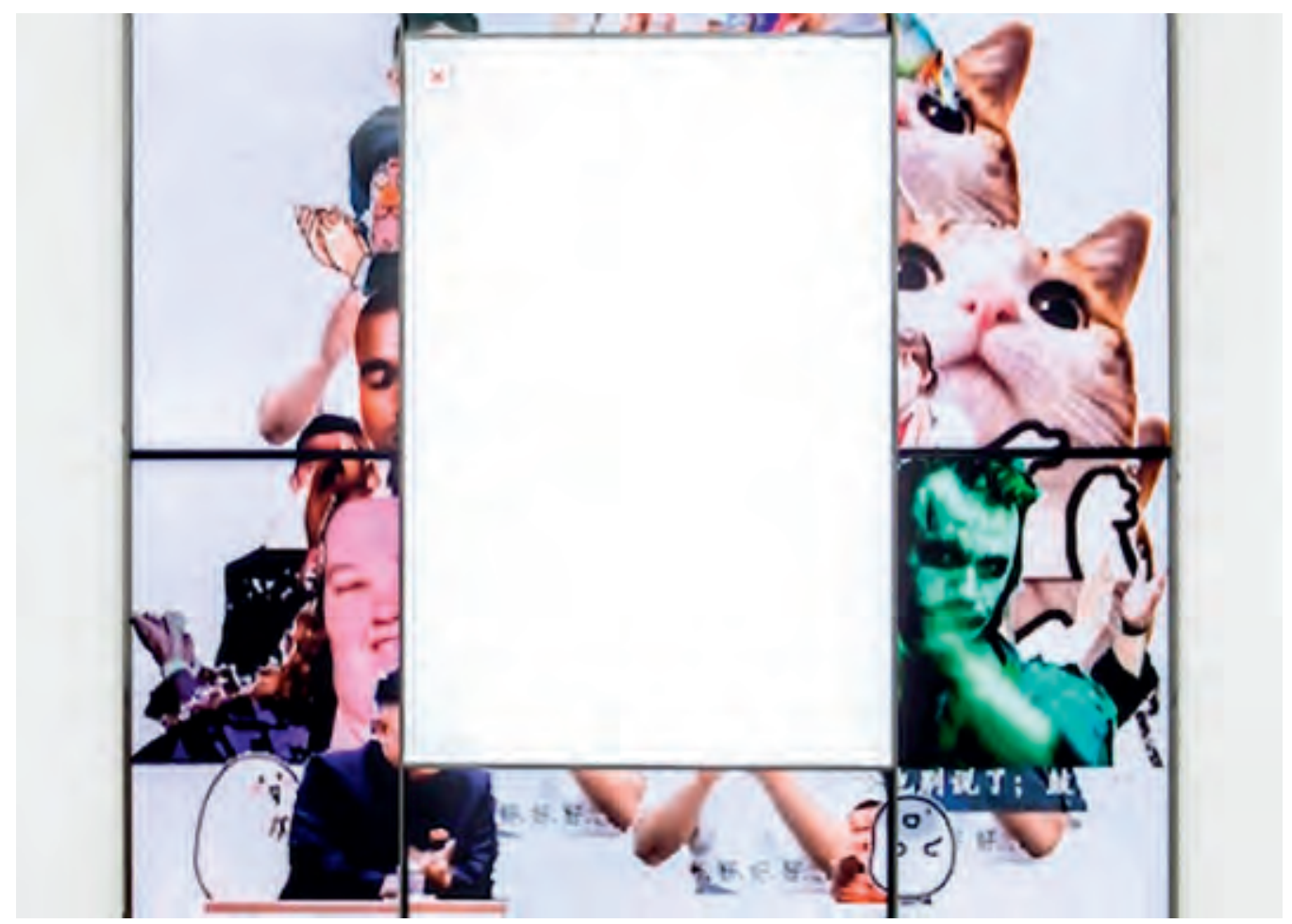

Imagen 4. Fotograma de "Problematic Gifs_No problem at all" de Miao Ying. Cortesía de la artista y "Madein Gallery". 


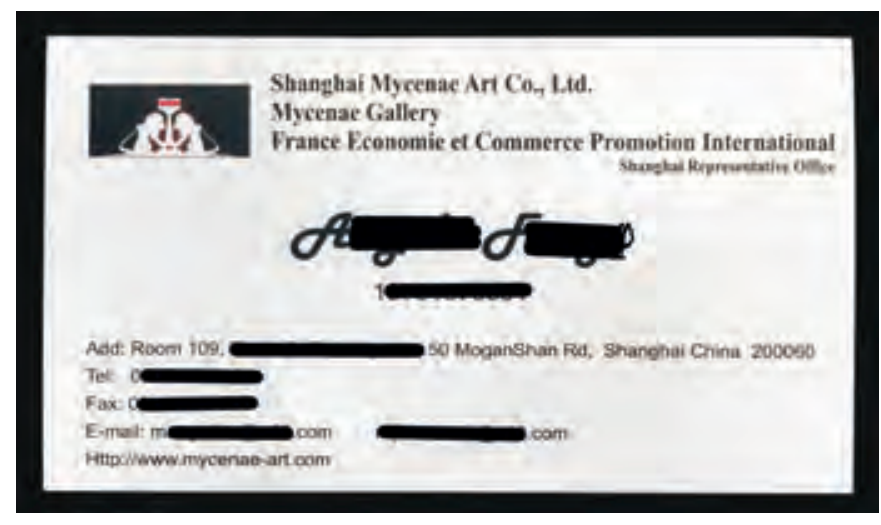

Imagen 5. Tarjeta profesional de los miembros de Mycenae Gallery.

tarjeta profesional de sus empleados, en la cual figura el nombre de la galería de forma conjunta con France Economic et Commerce Promotion International. Shanghai Representative Office. La confusión es generada como consecuencia de que en el espacio galerístico el autor del artículo nunca ha visto nada francés y, preguntados diferentes ciudadanos franceses por este tema -fuentes no oficiales-, nadie conocía de la existencia de semejante delegación, lo que sin terminante conocimiento al respecto y desde el conocimiento de la sociedad china y sus procederes, posiblemente sea un apoderamiento ficticio.

Después de los planteamientos realizados y atendiendo a ellos, la conclusión de este artículo es que, en un año en el que se ha realizado la undécima bienal de Shanghái, la ciudad ha perdido la oportunidad de terminar de explosionar galerísticamente aprovechando su buena situación económica, la edición de la bienal y la venida de la primavera, momento de optimismo y creación por antonomasia en la cultura china. Así se augura que muchas galerías seguirán abriendo y cerrando, ya que no dejan de ser establecimientos que se benefician de la existencia del dinero en circulación, algo que en China está presente y acaeciendo a niveles deslumbrantes. Hay, a su vez, también una gran cantidad de producción artística interesantísima. Ahora bien, si los galeristas, museos... son los embajadores del arte y de los artistas, China tiene todavía mucho trabajo por hacer, especialmente en una ciudad con el presente y la potencialidad de Shanghái. De lo contrario, puede que mucho caiga en el olvido y el abandono malgastando lo que, con el paso de los años, podría llegar a ser un gran patrimonio cultural de la República Popular China. Esto se ilustra con el último ejemplo y con el que cerraré este artículo: las galerías, en general, no aceptan que se tomen fotos de sus obras, algo que es un absoluto contrasentido si se tiene en mente una de las principales funciones que todo galerista tiene y debe realizar, a saber, la de promover y dar a conocer a los artistas que representa. ${ }^{8}$

\section{Referencias}

Fenollosa, E. (2011). Introducción a la cultura china. Santa Cruz de Tenerife: Melusina.

Fernández, I. (2002). El arte chino. Madrid: Historia Viva.

Kitaura, Y. \& Correa, A. (1991). Historia del arte de China. Madrid: Cátedra.

Kontler, C. (2002). Arte chino. Madrid: LIBSA.

Parrondo, J. \& Vega, J. (2002). Grabado y creación gráfica. Madrid: Historia 16.

Tregear, M. \& Vicens, A. (1991). El arte chino. Barcelona London: Ediciones Destino Thames and Hudson.

Zorrilla, J. (2006). China: la primavera que llega. Barcelona: Gestión 2000.

8 Es completamente cierto que las imitaciones suponen un grave problema en China. También lo es que el hecho de tomar fotos, en la actualidad, conlleva el riesgo implícito de que sean publicadas en internet y masivamente difundidas sin referencia. No obstante, hay estrategias para convertir esa circunstancia en una forma de buena publicidad, como muy bien han realizado las tiendas de moda en sus probadores, por poner solamente un ejemplo. En consecuencia, si se habilita a los visitantes a tomar fotos de las piezas y de la galería - tal vez sin flash por cuestiones de conservación-, ello podría suponer una importante oportunidad de difusión y conocimiento de los artistas en ellas representados. 